\title{
Retos y desafíos actuales de la educación como derecho humano
}

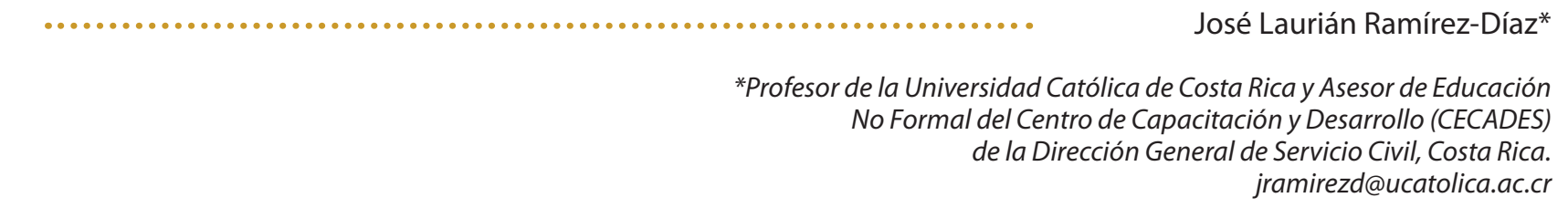

Recibido: 21 de setiembre del 2018 Corregido: 07 de noviembre del $2018 \quad$ Aceptado: 15 de noviembre del 2018

\begin{abstract}
Resumen
El documento plantea el análisis de algunos desafíos de la educación en la actualidad desde la perspectiva de los derechos humanos: la consideración de un enfoque de derechos y deberes humanos, la inclusión educativa, la cantidad de años de estudio, la influencia de la evolución tecnológica en el perfil del estudiantado, y la incertidumbre que caracteriza el futuro de la humanidad, todo analizado desde la perspectiva del humanismo. Así, se pretende profundizar en algunas situaciones necesarias de considerar por parte de profesionales en educación y del estudiantado mismo, especialmente por la crisis que afrontan las metodologías de enseñanza, tradicionalmente resistentes al cambio, en un mundo cada vez más globalizado que acelera y demanda los procesos de cambio, innovación, creatividad y adaptación.
\end{abstract}

Palabras clave: Educación, Derechos Humanos, Inclusión, Humanismo, Deberes.

\begin{abstract}
Challenges of education as human right at nowadays

This paper proposes an analysis of some challenges in today's education from human rights framework: the consideration of the human rights and human duties, the educational inclusive, the quantity of school years completed, the influence of the technology on student's characteristics, and the incertitude of the humanities future, all of these elements are considered from the Humanism. Thereby, the goal of this paper is the treat of some situations that the education's professionals need to know, also the students, in special because of the crisis of some actually learning methodologies what trying to resist the changes in a globalizing world that goes toward the development of skills as change capacity, the innovation, the creativity and the change adaptation.
\end{abstract}

Key words: Education, Human Rights, Inclusion, Humanism, Duties.

\section{INTRODUCCIÓN}

La educación, como proceso y derecho humano, ha sido objeto de análisis y evolución desde diferentes épocas y aristas, que han respondido a distintas situaciones históricas, ideologías, políticas sociales, tendencias económicas, incluso estrategias militares y hasta el adoctrinamiento. En la actualidad, impera un reconocimiento por el rescate del valor de lo humano, lo que influye en la educación y, a su vez, 
es replicado en los procesos que le constituyen, lo cual no debe verse como un fenómeno propio del presente, sino que requiere ser analizado desde sus consecuencias y planteamientos tanto en el pasado como a futuro, todo desde los distintos ámbitos involucrados, donde además de los derechos, los deberes humanos deben considerarse como criterio de equilibrio y parte importante de la educación para la convivencia social.

El ensayo repasa algunas consideraciones sobre los retos y desafíos de la educación, según plantean algunos enfoques contemporáneos, con el fin de repasar criterios que influyen en la integración de rutas analíticas que guíen la comprensión holística del fenómeno educativo, desde un enfoque humanista de derechos y deberes humanos.

\section{EL HUMANISMO Y LA EDUCACIÓN COMO DERECHO HUMANO: SUS RETOS Y DESAFÍOS}

Para iniciar, se dirá que la educación formal es aquella recibida en las aulas o centros educativos; no obstante, no se limita a esta modalidad, ya que comprende diferentes contextos. Desde un punto de vista biológico y considerando el objetivo clave de la educación, el cerebro humano está diseñado para aprender a través de las experiencias, las cuales se traducen en recuerdos y estas, a su vez, en conductas; una vez dada esta última, es cuando se refiere a un aprendizaje (Carslon, 2014; Mellerup, 2015).

Actualmente, además del uso en procesos integrados de enseñanza aprendizaje, es común que las personas utilicen distintas plataformas tecnológicas para aprender materias muy específicas por ellas mismas, lo cual forma parte de un tipo de educación informal, ya que es casuística, generalmente fortuita, y responde a un objetivo inmediato como puede ser un vídeo que se observa para aprender alguna receta.

La educación no formal, por su parte, presenta una estructura didáctica, habitualmente evaluada, pero que no siempre responde a una demanda generalizada, como sucede con la educación formal; ejemplo de esta pueden ser las actividades de capacitación profesional. Así mismo, la educación formal y la no formal certifican el conocimiento a través de títulos o grados, situación de la cual carece la educación informal. Es necesario considerar que no solo el ser humano tiene la capacidad de aprender, ya que ciertos animales lo hacen, pero la educación considera un fenómeno que sí lo implica exclusivamente como especie.

Al respecto de lo anterior, León (2007) señala:

La educación es un proceso humano y cultural complejo. Para establecer su propósito y su definición es necesario considerar la condición y naturaleza del hombre y de la cultura en su conjunto, en su totalidad, para lo cual cada particularidad tiene sentido por su vinculación e interdependencia con las demás y con el conjunto. (p. 596)

La educación es compleja porque, entre otras cosas, obedece y responde a la cultura, una esfera humana que presenta altos niveles de dificultad en su análisis y comprensión. A propósito, se considera necesario introducir el concepto del humanismo, un elemento central dentro del análisis en este documento, el cual planteó las bases de la educación como derecho humano, según la Organización de las Naciones Unidas para la Educación, la Ciencia y la Cultura (UNESCO, 2012). Pero el sistema educativo actual presenta algunas condiciones que deben considerarse y ser replanteadas, si se desea proponer procesos humanistas de educación integral. A continuación se analizan algunas.

Primeramente, es necesario considerar ciertos antecedentes del sistema de educación formal actual. Si bien existieron movimientos e ideologías anteriores, fue en el siglo XIX, en Prusia, que se replicaron 
los pensamientos de Johan Friedrich Herbart, quien basó el aprendizaje sobre aptitudes, habilidades e intereses del estudiantado sobre métodos de adoctrinamiento, maximizando el aprovechamiento de la totalidad de los recursos tales como el profesorado, el espacio para recibir lecciones y otros (Zorrilla, 2002). Fue entonces que la educación, como proceso, tomó como base algunos intereses y criterios elitistas de tipo político y social, donde fueron incorporados, por parte de la monarquía, elementos de la ilustración para complacer al pueblo, manteniendo el régimen absolutista y dividiendo a la sociedad en clases y castas, una situación que se había implementado en la antigua Esparta (Reevo, 2012). Estos modelos parecen replicarse en la sociedad actual, en donde la educación muestras diferencias notorias según zonas geográficas o entre el modelo público respecto al privado.

Tal como le ha sucedido a la educación, Núñez y Aular (2013) explican que el humanismo se ha alimentado de distintas etapas históricas: la clásica, la renacentista y la ilustrada. Respecto a la primera destaca a Sócrates como máximo representante, para quien existían conceptos necesarios de conocer objetivamente: justicia, amor y virtud y conocimiento de uno mismo. En el Renacimiento, la consideración del humanismo se dio como consecuencia de la evolución social e ideológica europea, la cual derivó en la revolución científica a partir de la consideración racional del ser humano. Explican Núñez y Aular (2013) que:

Es precisamente en la etapa renacentista cuando se da apertura al uso del término «humanista» para referirse a la liberación de la ignorancia y el dogmatismo de «la edad de las tinieblas» e ir en búsqueda de la verdad, la belleza, la libertad y la dignidad humana. (p. 670)

Como puede verse, el humanismo clásico aprecia a la ética y el renacentista a la estética, a lo que se suman la libertad y la dignidad humanas. Finalmente, en el humanismo ilustrado Fromm (1985), citado por Núñez y Aular (2013, p.672), explicó que se enseñó al ser humano "que puede confiar en su propia razón como guía para establecer normas éticas válidas y que puede depender de sí mismo, sin necesitar de la revelación ni de la autoridad de la Iglesia para saber lo que es bueno y malo". En este sentido, la razón humana se posicionó como la piedra angular del conocimiento, basado en una ética e ideologías políticas sustitutivas del dogmatismo que caracterizó a la Edad Media y anteriores.

Según Copson (2015), nadie inventó o encontró el humanismo, sino que el término describe una relación de ideas y valores que, por siglos, han constituido una arista no religiosa y evolutiva de una noción presente durante unos dos mil quinientos años, y que ha sido descrita como una visión de mundo, forma de vida o actitud ante la existencia; también se le ha considerado como una vivencia o un estilo de vida. En este sentido, Law (2011) coincide en decir que las raíces del humanismo se remontan al mundo antiguo, cuyas primeras referencias se remontan en la India, en el siglo VI a.C.

En la actualidad, el humanismo ha cobrado especial relevancia posterior a la II Guerra Mundial, materializándose en la propuesta de los derechos humanos (Davies, 2008), lo que implica una de las mayores apuestas de la educación en la actualidad: la garantía de incluir a todas las personas, basada en el respeto a las diferencias, en consideración de criterios como el género, la etnia, los estilos de vida particulares que no afecten la integridad de terceros, entre otros. El discurso humanista contemporáneo plantea un amparo a la diversidad, donde el dogma cede espacio a la vivencia particular, un escenario sobre el cual se pueden considerar ciertos retos y desafíos de la educación como derecho humano.

Antes de referirse a la educación como derecho, es necesario indicar que en este caso, el humanismo será entendido a partir de la diada de los derechos y deberes, ya que particularmente se considera que existe una tendencia preferente de demanda hacia los primeros, dejando de lado la responsabilización de las acciones, siendo ambos considerandos sumamente importantes para un desarrollo armonioso a nivel individual, social, ético, político e, incluso, cultural. Con esto no se pretende decir que el avance en derechos humanos haya sido errado, sino que debe considerarse la conjunción de todos los elementos 
que componen a cada uno de los desafíos que destacan en la actualidad, dentro de los cuales figura la inclusión educativa y social, lo cual será explicado más adelante.

Según la Unión Interparlamentaria de la Oficina del Alto Comisionado de la Organización de Naciones Unidas (ONU, 2016), los derechos humanos parten de la dignidad inherente que posee toda persona, y que "definen las relaciones entre los individuos y las estructuras de poder, especialmente el Estado" (ONU, 2016, p.19). Sobre el tema ha existido una discusión continua a lo largo de varias décadas, de la cual se han logrado avances importantes a nivel colectivo e individual, tales como la inclusión del respeto hacia la diversidad en los contextos de formación, así como las políticas para integrarla en los procesos sociales, liderados desde disposiciones vinculantes para el servicio de las instituciones públicas y privadas en la mayoría de los casos.

Respecto a lo anterior, el primer desafío por considerar es, precisamente, la incorporación de los deberes humanos como parte de los considerandos de la educación actual ya que, como se mencionó, parecen estar relegados a un segundo plano, situación necesaria de atender ya que, según explica Daros (2013), los derechos y los deberes son correlativos dentro de una justicia social. En este sentido, un deber ha de ser proporcional a la capacidad de su cumplimiento (Sant'Ana, 2014). Con base en esto, a nivel particular se piensa que un derecho no debe imponerse abruptamente sobre el respeto e integridad de un colectivo de personas. Entiéndase que en la esfera social, toda persona practica repertorios de conductas con base en criterios propios, entre los cuales destacan diversas áreas como la familiar, la personal, la comunal, la sexual, entre otras. Se propone, así, un análisis desde los derechos y deberes humanos, ya que la educación plantea, en sí misma, garantías y requerimientos en el cumplimiento respectivo de ambos considerandos.

La era actual está caracterizada por la globalización, un fenómeno multicausal que posee, como uno de sus vehículos, el desarrollo tecnológico, lo que "ha provocado que los valores morales, éticos y la solidaridad sean sustituidos por un "ciudadano consumidor»" (Castillo y Gamboa, 2012, p.57). En este sentido, la humanidad ha sido alienada por una cultura de consumo que irrespeta varias de sus dimensiones, situación que la educación debe asumir como uno de sus desafíos, favoreciendo la comprensión y respeto de la diversidad cultural, en la cual se superen los paradigmas de enseñanza tradicionales de adoctrinamiento, donde la individualidad no sea antepuesta al bien común, una situación que tiene a la vida y al planeta en sí a punto de colapsar (Correa y Forero, 2016; Ramírez, 2016). Otro desafío, el segundo del listado, se relaciona con la calidad de la educación, la cual requieren trascender de la simple memorización hacia métodos promotores de la conciencia crítica, la reflexión y el bienestar colectivo, aspecto del que se hablará más adelante.

Vale decir, retomando lo descrito líneas atrás, que el bienestar común se relaciona con la búsqueda del cumplimiento de las condiciones para que todas las personas tengan acceso a los mismos derechos; esta situación implica el deber de las instituciones y las personas mismas de garantizarlo mediante acciones particulares y colectivas. El acceso a las oportunidades de todas las personas en igualdad de condiciones, tanto en el ejercicio del derecho como en la atención a los deberes y su cumplimiento, demanda un accionar articulado a partir de la justicia social, lo cual presenta estrecha relación, tal como se especificó párrafos atrás, con los derechos y derechos humanos, ambos por igual.

Lo anterior plantea la necesidad de asumir la responsabilidad propia y no delegarla a terceros, de modo que se asuma una actitud proactiva en la búsqueda del equilibrio social por parte de todas las personas, sin distingo por las características particulares de etnia, cultura, lugar de residencia, clase social u otras. En este sentido, existe un concepto que concentra una elevada discusión en la actualidad y que engloba los elementos que hasta ahora se han considerado, el cual vale la pena analizarlo como otro desafío de la educación: la inclusión educativa. 
La inclusión educativa tuvo sus primeros debates alrededor de la educación especial y las oportunidades que estudiantes de dicha modalidad podían tener con las ofertas formativas que se les ofrecían (Soto, 2003; Infante, 2010; Segura y Martínez, 2014). Aunque el término ha evolucionado en los últimos años, "al hablar de inclusión se habla de tolerancia, respeto y solidaridad pero, sobre todo, de aceptación de las personas, independientemente de sus condiciones" (Soto, 2003, p.3). El mismo autor expone que la inclusión educativa es un hecho social, no natural, es decir, que si bien existen condicionamientos físicos, de la biología y del entorno, la inclusión trasciende hacia acciones de tipo político o de facilidades para favorecer el acceso a las oportunidades entre todas las personas, lo cual implica un derecho que debe garantizarse desde los ámbitos jurídicos y colectivos pero que, a su vez, constituye un deber que involucra a todas las personas por igual, tanto en el acceso como en la demanda de posibilidades para el desarrollo personal y colectivo. No solamente las instituciones pueden limitar oportunidades, sino personas a nivel particular mediante actitudes carentes de conocimiento o compromiso.

Existe otro asunto crítico en la actualidad, además de los anteriores, el cual refiere a la cantidad de los años de estudio o al nivel de escolaridad, el cual presenta un importante impacto en el mejoramiento de las condiciones de la calidad de vida y la lucha contra la pobreza, lo que constituye el cuarto desafío de este listado, el cual radica en la necesidad de aumentar los años de escolaridad de la ciudadanía a un mínimo de 12, aunque ha de aceptarse que esta cantidad sigue siendo insuficiente en el marco de las demandas actuales.

Avilés (2012) menciona que la educación es, teóricamente, la opción más viable para que los países menos desarrollados doten a la ciudadanía de herramientas para mejorar sus condiciones de vida y transcender a la miseria y la escasez, por lo que no es casualidad que varios esfuerzos y acuerdos internacionales consideren la necesidad de alcanzar, como promedio, 12 años de escolaridad formal.

Sobre la concepción de pobreza, esta no debe ser entendida como falta de recursos económicos o materiales, sino que debe integrar otros aspectos como la dimensión espiritual y la necesidad de transcender, además de la realización personal, la generatividad personal y social en contextos de trabajo y comunales, entre otros. Sin embargo, el derecho a la educación inclusiva presenta algunas limitaciones, ya que no todas las personas tienen acceso a las mismas oportunidades de inclusión o cuentan con una cantidad de años de escolaridad suficiente, lo cual puede sesgar el mejoramiento en la calidad de vida y el progreso tanto a particular como social. Mucho se debate sobre el acceso a las oportunidades para mejorar los estándares de vida, las cuales deben ser las mismas para todas las personas, pero existen brechas sin resolver tales como los estándares en la calidad de la educación y los recursos disponibles en la formación de escuelas de zonas urbanas y rurales, solo para citar un ejemplo, lo que plantea una desigualdad sin justificación salvo el lugar donde viven unas y otras personas.

Si desde el humanismo se plantea el respeto a la diversidad como pilar de la educación inclusiva, dentro de lo que se incluye la poca relevancia de la procedencia de las personas, así como el respaldo del enfoque de los derechos humanos, los cuales son inherentes a la condición humana y, por ello, irrenunciables, las brechas en este sentido son una antítesis de los objetivos que se desean alcanzar y sobre los cuales se han dado acuerdos internacionales, pero que por las condiciones de los países de América Latina presentan varias dificultades en su logro. Esto no sólo incrementa las diferencias a nivel social, sino que pone en desventaja a las personas por condiciones ajenas a ellas en la mayoría de las ocasiones. La educación, por tanto, debe asumir el desafío de resolver esta y otras situaciones similares, para procurar una sociedad cada vez más justa.

La situación se complica más cuando se analiza el ámbito de alcance real de la inclusión, la cual se aplica también al entorno colectivo, es decir, a la consideración de una sociedad inclusiva (Castillo, 2015). Lo anterior sugiere que, además de los retos anteriores, podría sumarse uno más, que incide directamente sobre el resto: el limitado presupuesto para educación que caracteriza a la mayoría de naciones en vías de desarrollo. Existen serias limitaciones en este sentido en varios países de latinoamérica, de modo que 
es necesario un replanteamiento de algunos considerandos actuales de la educación, en donde debe concebírsele como una inversión, situación que aún no ha podido lograrse a cabalidad, pero que además del derecho que implica, conlleva el deber de la ciudadanía en pedir cuentas a las clases políticas sobre las inversiones públicas que hacen y su verdadera conveniencia social, en donde la educación debería estar como una prioridad y, además, con una inversión suficiente basada en resultados.

La sociedad inclusiva trasciende a los ámbitos escolares, pero los considera vehículos de aprendizaje, promoción y fuentes de réplica de los mismos, considerando su ensayo desde edades tempranas. En este sentido, es importante rescatar que algunos contenidos transversales de los procesos educativos deberían consolidarse como parte de la currícula formal educativa, tales como el respeto e integración de todas las personas a la participación social, la consolidación y garantía en el ejercicio de los derechos entre hombres y mujeres de todos los estratos sociales, así como el reconocimiento y cumplimiento de los deberes, la exigencia y mantenimiento de procesos educativos de calidad, entre otros. Estas situaciones son complejas y responden a criterios de cambio cultural y a una época contemporánea que se distingue por constantes cambios, situación que implica el último de los retos y desafíos de la educación, considerados en este listado: el perfil del estudiantado actual.

En líneas atrás se consideró la influencia contemporánea de la tecnología en todos los aspectos de la vida cotidiana. Como nunca antes, las personas acceden a cantidades inimaginables de información de forma inmediata, por lo que son muchas las demandas hechas al cuerpo docente, entre las cuales se pueden citar el desarrollo de la capacidad crítica, la reflexión, las capacidades de innovación y creatividad, así como la participación en redes de conlaboración entre el estudiantado (Arce y Medina, 2016). En este sentido, se plantea el derecho de cada discente por una educación ajustada a sus necesidades, pero también al deber de distintos actores sociales en procurarla, mantenerla, supervisarla y evaluarla, tanto a nivel económico como político. Sin embargo, las tareas no son competencia exclusiva de los centros de enseñanza o autoridades estatales, sino que deben ser un compromiso compartido entre estos y las personas beneficiarias.

Respecto a lo anterior, y considerando los deberes, la educación debe alentar la responsabilización de las personas sobre sus acciones. Estos son considerandos del humanismo y de la educación como derecho, sobre los cuales se fundamentan aspectos de suma valía que proporcionan posibilidades a las personas para definirse a sí mismas en su contexto particular, a nivel existencial, personal, espiritual y social.

La consideración exclusiva de los derechos humanos en los ámbitos educativos no garantiza las mismas posibilidades de crecimiento que ofrece la diada de estos en conjunto con los deberes, estos últimos como garantes de la satisfacción de necesidades y obligaciones que toda persona debe aceptar e incluir en su trato e interrelación con su entorno. En este sentido, a nivel particular se considera que no puede existir un verdadero equilibrio social e individual si se plantea solo el enfoque de derechos, carente de deberes, un reto que integra a todos los demás que aquí se mencionan, ya que apuesta al balance y equilibrio que, a nivel social, se demanda a la educación.

Ante esto, el desaparecido escritor portugués y ganador del Premio Nobel de Literatura 1998, José Saramago, dijo alguna vez: "Nos fue propuesta una Declaración Universal de Derechos Humanos y con eso creímos que lo teníamos todo, sin darnos cuenta de que ningún derecho podrá subsistir sin la simetría de los deberes que le corresponden" (Argüello, 2018, parr.2). En la actualidad, la sociedad vive en una época revolucionaria en la cual reivindica los derechos que han sido negados en ciertos momentos históricos por condiciones étnicas, de religión o incluso el género, lo cual es una lucha justa y necesaria y que aún, lamentablemente, no se ha resuelto, pero que no debe obviar las normas que prevalecen ante cualquier acto humano, es decir, la responsabilidad que tienen las personas sobre sus acciones.

En medio de cualquier lucha social existen ideologías que no avanzan al ritmo de los cambios culturales, y es que toda sociedad está compuesta por personas de distintos pensares, lo cual es necesario para la 
evolución y equilibrio social, pero que a veces constituye un elemento que debe sortearse para alcanzar los objetivos trazados. Ante esto, particularmente se cree que una de las formas de protección de ciertos vicios es la consideración de los deberes de la humanidad, situación que aunque no es novedosa, a veces parece serlo por su olvido en los últimos años, al menos en varios discursos de luchas sociales contemporáneos. De poco vale la demanda de los derechos si no existe un ejercicio autónomo y responsable de estos, así como la creación, seguimiento y evaluación de las condiciones que para ello se generen, lo cual incluye per se a los deberes.

Respecto a los derechos humanos, la Organización de Naciones Unidas (ONU) indica que el cumplimiento de estos se relaciona con el desarrollo económico, político, social y cultural de una nación y sus habitantes (Sotillo, 2015). Empero, retomando la necesidad de los deberes, estos se plantean desde la ética de las acciones humanas, lo cual retoma el camino hacia los deberes. José Saramago, citado por Sánchez (2015), describió algunos de estos, a saber:

- Erradicar el hambre y no desperdiciar alimentos.

- Acabar con el analfabetismo y educar con calidad.

- Compartir el conocimiento y la pericia para alcanzar una salud integral.

- Medicamentos gratuitos o de precio justo.

- Regulación del Estado sobre precios de medicamentos y leyes que regulen el mercado.

- Veracidad y respeto del derecho de libertad de expresión.

- Usar la energía de manera eficiente y tomar medidas para su ahorro.

- Eliminar la desigualdad extrema de las sociedades.

- Ofrecer hospitalidad a inmigrantes y refugiados.

- Proporcionar condiciones óptimas para la libre competencia entre empresas.

- Regular el mercado para incrementar la riqueza mundial y el bienestar individual.

- Pagar impuestos.

- Enfocar el conocimiento científico hacia la preservación de la vida.

- Respetar el medio ambiente y contribuir con su descontaminación y preservación.

- Respeto por el hábitat y la vida de animales no humanos.

Si se analiza detenidamente, estos deberes tienen una conveniencia bastante oportuna para muchos retos y desafíos del derecho a la educación. De no existir tales, las personas no tendrían responsabilidad sobre las consecuencias de sus actos, así como tampoco de las repercusiones que tienen en su contexto y, por qué no decirlo, en el planeta, lo que puede ser uno de los panoramas más negros e inseguros que plantearía la consideración única de los derechos humanos, al alejarse de la responsabilidad que demandan las acciones y el ejercicio de las libertades de las personas. Por tanto, el balance de los procesos educativos para la construcción de una sociedad justa es un desafío que engloba a la mayoría de los retos actuales.

"El ser humano es libre y esa es su condena" dijo Paul Sartre, citado por Ramírez (2015). La consideración integral de cada persona, entonces, trasciende su propia existencia, y centra su atención en sus actos y la motivación para realizarlos. Lo anterior involucra, a criterio particular, las acciones consideradas a partir de sus repercusiones futuras, que no solo implican los derechos y deberes de las personas que habitan el planeta en la actualidad, sino a las posteriores generaciones.

Fenómenos complejos y de serias repercusiones como la violencia, las drogas, el calentamiento global, el cambio climático, la extinción de especies de flora y fauna, la sobreexplotación de recursos naturales a un ritmo mucho más acelerado que la capacidad regenerativa del planeta, entre otros, plantean serios desafíos a la educación actual, además de promover la exclusión social y el riesgo a la supervivencia de la vida en el planeta, incluyendo a la de la humanidad, situaciones que no se pueden analizar desde una arista única de derechos humanos, sino desde los deberes individuales y colectivos, que 
deberían considerarse desde una educación humanista integral, así como los desafíos que esta presenta en la actualidad.

Actualmente, el ser humano vive una época caracterizada por la incertidumbre. El futuro, tiempo que nunca ha sido comprendido en su totalidad e inexistente desde varios planteamientos, propone un desconocimiento casi total de lo que sucederá en los próximos años. Las consecuencias de las acciones presentes muestran rutas más complejas de analizar y prever. Como nunca antes, la humanidad tiene más dudas que respuestas sobre situaciones claves como el trabajo, el entorno en el que se desarrolla, las condiciones óptimas para la vida en el planeta, incluso el desarrollo tecnológico, el cual ha sido un vehículo importante de avances significativos, pero que también ha desplazado a uno de los elementos más preciados para las personas: su humanidad misma.

Asimismo, la humanidad no puede ser ajena a valores como el respeto por la vida y el compromiso hacia el bienestar de las futuras generaciones, condiciones que ya se han analizado a partir del derecho a la educación y sus desafíos actuales. De otra forma, ¿de qué valdría el esfuerzo de cualquier nación o la humanidad como un todo si su supervivencia está en riesgo? El esfuerzo por atender los retos actuales tiene, entre otros, un objetivo de primer orden: garantizar la subsistencia de la vida en el planeta. Alejado de estos criterios, el humanismo y los derechos humanos no serían más que una nebulosa intelectual que promueve el comportamiento narcisista, el cual explica gran parte de las crisis en la actualidad y que desafían a la educación por brindar libertades sin límites claros que planteen el análisis de las acciones individuales y colectivas, así como su impacto en el contexto planetario.

Con respecto a lo anterior, es relevante considerar los planteamientos de Édgar Morín, citado por Aranibar (2010), quien expuso siete saberes necesarios en la presente era de la incertidumbre:

1. Una educación que cure la ceguera del conocimiento. La educación debe considerar el error y la ilusión como elementos posibles de la educación.

2. Una educación que garantice el conocimiento pertinente. En la actualidad se debe discriminar la información, así como determinar cuáles problemas son más importantes de resolver que otros.

3. Enseñar la condición humana. Todas las personas deben reconocerse en su humanidad común y, paralelamente, reconocer la diversidad cultural inherente a todo lo que es humano; es situar a cada persona en el universo y, al mismo tiempo, separarla de él.

4. Enseñar la identidad terrenal. Considerar la educación desde una perspectiva planetaria, promovida en especial por la tecnología y las facilidades que brindan para la comunicación en la actualidad.

5. Enfrentar las incertidumbres. Superar la idea de que el futuro se conformará de acuerdo con las creencias e instituciones actuales. En este sentido, la incertidumbre no solo radica en el futuro, sino en la validez del conocimiento y las propias decisiones.

6. Enseñar la comprensión. Es necesaria incentivar la comprensión en dos niveles: a) interpersonal e intergrupal y b) a escala planetaria. En este sentido, "la verdadera comprensión exige establecer sociedades democráticas, fuera de las cuales no cabe ni tolerancia ni libertad para salir del cierre etnocéntrico" (Aranibar, 2010, p.77).

7. La ética del género humano. Es necesaria la enseñanza de una ética válida para todos los seres humanos en donde, sin lugar a dudas, los deberes son pilares para ello.

La educación debe considerar varios ámbitos de acción, pero también es necesario recalcar que el humanismo, corriente filosófica que favoreció la consolidación contemporánea de los derechos humanos, está en crisis. Al respecto, Ors (2010, p.2) explica que "paradójicamente de lo que se dan cuenta los 
críticos del humanismo moderno es de que el principal fruto de la modernidad es la ciencia, que en vez de convertirnos en humanos nos habría deshumanizado". El humanismo, entonces, debe hacer frente a la propia libertad que promovió en la humanidad, la cual ha derivado en una capacidad inventiva que le ha constituido en, precisamente, un ser influido por su propia creación, que le ha deshumanizado en algunos aspectos, especialmente en la comunicación e interacción con el planeta.

Sobre la comunicación, es interesante analizar que el ser humano ha evolucionado en su ámbito social a partir la la interacción con sus semejantes, mirando su rostro y cuerpo para interpretar el sentido más allá de lo verbal; al respecto García $(2012$, p.12) explica que "cuando hablamos de la comunicación no verbal, nos referimos a todos aquellos mensajes que enviamos sin hacer uso de la palabra. Hablamos de gestos, expresiones, movimientos corporales, contacto visual... toda una serie de señales que tienen mucha importancia en la relación entre las personas". La mayoría de los canales tecnológicos presentan algunas limitaciones en la comunicación no verbal, de la cual Corrales (2012) explica que, en los seres humanos, la comunicación no verbal "es frecuentemente paralingüística, es decir, acompaña a la información verbal matizándola, ampliándola o mandando señales contradictorias" (p.47). La comunicación a través de plataformas tecnológicas se ve limitada, en su mayoría, a canalizar solo la palabra dicha o escrita, de modo que el sentido de los mensajes pueden tergiversarse y, como una consecuencia de ello, se ha tendido a la individualización, la cual, en extremo, no genera posibilidades de crear una conciencia de bienestar común.

El rasgo de comunicarse no verbalmente es predominantemente humano, y la tecnología ha planteado, poco a poco, un desplazamiento de ésta por otras formas de interacción y, por tanto, del ejercicio de la humanidad como tal, lo que plantea el principal foco de crisis de esta corriente filosófica, y una de las razones para considerar y reclamar no solo los derechos, sino los deberes en ámbitos de similar relevancia.

Retomando la necesidad de considerar los derechos y deberes como centro de los desafíos de la educación actual, el dotar de una libertad total, sin límites racionales, ha sido una fórmula planteada en distintos ámbitos con resultados que no han generado mayores beneficios en muchos casos. Ejemplo de ello ha sido la "libertad" del capitalismo, que ha puesto en jaque la sostenibilidad de los recursos y la vida en el planeta.

El mercado también ha gozado de libertades sin mayor control y como consecuencia surgió el consumismo, con repercusiones alienantes en las personas (Ramírez, 2016). A nivel particular se considera que, si bien el humanismo plantea la libertad como uno de sus principios, y los derechos como garantía de la integridad de la condición humana, es necesario enfatizar la responsabilidad que conlleva todo acto humano como una estrategia y elemento de autoprotección. Al fin y al cabo, la convivencia en sociedad demanda comportamientos apropiados, los cuales se plantean dentro de una cultura, época histórica, códigos éticos y otros elementos particulares que, si bien pueden variar en el tiempo y el espacio, dictan los parámetros de la sana convivencia, lo cual es regulado por la disciplina del Derecho (Honoré, 2015).

De este modo, entre los retos de la educacón contemporánera se encuentra la alusión a los deberes humanos, lo cual implica la consideración de la responsabilidad sobre los actos, un principio basado en la intención de las acciones, o como se conoce en Derecho, la causa de estas (Rodríguez, 2004). Es necesario, por tanto, dotar a las personas del sentido crítico de sus decisiones y las consecuencias derivadas, un desafío de la educación la cual, como derecho humano, está llamada a aportar en esta importante misión, la cual es compartida por otras esferas sociales como la familia y la sociedad. Aun cuando el humanismo, principio epistemológico de los derechos humanos, esté afrontando algunas situaciones críticas, su rol no ha concluido, y de hacerlo, debe plantear nuevas formas de analizar, entender y afrontar la realidad y sus desafíos a través, en este caso, de la educación. 


\section{CONCLUSIONES}

Dentro de los retos y desafíos de la educación en la actualidad, el humanismo ha sido una filosofía presente a lo largo de la historia de la humanidad, la cual ha planteado rescatar el elemento más representativo de la humanidad misma, lo cual dio pie al enfoque de derechos. La educación, un proceso exclusivo e inherente a la especie, se ha involucrado en la promoción de esta visión desde tiempos remotos. Como proceso, ha sido uno de los vehículos más importantes en la constitución del ser humano a nivel cultural, personal y social, y ha asumido retos y desafíos a lo largo de su existencia, donde la calidad, la inclusión y la consideración tanto de derechos como de los deberes enmarcan algunos de los más importantes en la actualidad.

Respecto a lo anterior, los derechos humanos requieren del ejercicio en paralelo de los deberes, los cuales se necesitan para un balance adecuado entre las acciones y la ética de los actos respectivamente, con el fin de construir una sociedad más justa, uno de los objetivos a los que apunta la educación. Como se analizó, los derechos necesitan de la responsabilización de las personas, no solo para ejercerlos, sino para demandar las condiciones necesarias para ello. La inclusión educativa demanda de ciertas condiciones para establecerse en pleno, situación que deriva, también, en el deber.

La época actual es incierta y el futuro también, de modo que la educación afronta desafíos de distinto orden, pero que le demandan la mejora de su calidad y la ampliación de su alcance a todas las poblaciones, especialmente por condiciones de acceso geográfico. Por esta razón, la educación debe preparar a las personas para ser autónomas y responsables de sus decisiones y actos sin importar su procedencia, etnia y demás características. La diversidad nutre los procesos educativos, de modo que la solución a este desafío guía hacia imnumerables beneficios.

Asimismo, no debe caerse en el engaño ante la aparente confortabilidad que brinda el humanismo como fundamento de los derechos humanos, especialmente en momentos de tantos cambios. Ante esto, es necesario propiciar el debate permanente sobre nuevas visiones de mundo que promuevan, entre otras cosas, principios constitutivos de la educación, analizada desde los paradigmas de los derechos y deberes humanos, así como los desafíos que la era actual plantea sobre la educación.

\section{REFERENCIAS}

Aranibar, D. (2010). Los siete saberes según Édgar Morín. Gaceta Médica Boliviana, 33(1), 76-78. Recuperado de http://www.scielo.org.bo/pdf/gmb/v33n1/a15.pdf

Arce, R. \& Medina, I. (2016). Retos de la educación superior ante nuevas características de estudiantes nuevos retos docentes. En Márques, L. y Ahumada, A., La Universidad Pública en México y su compromiso social (pags. 66-74). Ciudad de México: ECORFAN-México.

Argüello, J. (2018). Debate. La hora de los deberes humanos. Diario el Clarín. [Versión en línea]. Recuperado de https://www.clarin.com/opinion/hora-deberes-humanos_0_r1wu57B2M.html

Avilés, G. (2012). Retos y desafíos de la educación costarricense. InterSedes: Revista de las Sedes Regionales, 13(26), 105-122. ISSN: 2215-2458.

Carslon, N. (2014). Physiology of behavior. (11 $1^{\text {th }}$. ed.). New York: Pearson.

Castillo, C. (2015). La educación inclusiva y lineamientos prospectivos de la formación docente: una visión de futuro. Revista Electrónica Actualidades Investigativas en Educación, 15(2), 1-33. https://doi. org/10.15517/aie.v15i2.18534

Castillo, M. \& Gamboa, R. (2012). Desafíos de la educación en la sociedad actual. Diálogos educativos, 12(24), 55-69. ISSN: 0718-1310. 
Copson, A. (2015). The Wiley Blackwell Handbook of Humanism. New Jersey: John Wiley \& Sons, Ltd.

Corrales, E. (2012). El lenguaje no verbal: un proceso cognitivo superior indispensable para el ser humano Revista Comunicación, 20(1), 46-51. ISSN: 0379-3974.

Correa, L. \& Forero, A. (2016). Desafíos en educación superior para las ciencias sociales. Tendencias, 17(2), 126-135.

Daros, W. (2013). La invisibilización de los deberes humanos universales. Enfoques, 25(2), 9-31. Recuperado de http://www.scielo.org.ar/pdf/enfoques/v25n2/v25n2a02.pdf

Davies, T. (2008). Humanism. The new critical idiom. (2 ${ }^{\text {nd }}$. ed.). New York: Routledge.

García, A. (2012). Cuando el cuerpo comunica. Manual de la comunicación no verbal. (Trabajo final de graduación para optar por el grado de licenciatura en Comunicación Audiovisual, Universidad Politécnica de Valencia). Gandia, España.

Honoré, T. (2015). La causalidad en el Derecho. Enciclopedia de Filosofía y Teoría del Derecho, vol. 2, 14791499. Ciudad de México: Universidad Autónoma de México, Instituto de Investigaciones Jurídicas.

Infante, M. (2010). Desafíos a la formación docente: inclusión educativa. Estudios Pedagógicos, 36(1), 287297. Recuperado de http://mingaonline.uach.cl/pdf/estped/v36n1/art16.pdf

Law, S. (2011). Humanism. A very short introduction. New York: Oxford University Press.

León, A. (2007). ¿Qué es la educación? Educere, 11(39), 595-604. ISSN: 1316-4910

Mellerup, S. (2015). Recuerdo y memoria, componentes esenciales en tres cuentos de Juan José Saer. Diálogos Latinoamericanos, (24), 88-103. ISSN: 1600-0110. Recuperado de http://www.redalyc.org/ pdf/162/16242735007.pdf

Núñez, C. y Aula, L. (2013). El Humanismo contemporáneo como fuente y fundamento de los derechos fundamentales. Revista de Derecho UNED, (12), 667-688. Recuperado de http://e-spacio.uned.es/ fez/eserv/bibliuned:RDUNED-2013-12-6105/Documento.pdf

Organización de las Naciones Unidas. (2016). Derechos humanos. Manual para Parlamentarios No 26. [Documento digital]. Recuperado de https://www.ohchr.org/Documents/Publications/ HandbookParliamentarians_SP.pdf

Organización de las Naciones Unidas para la Educación, la Ciencia y la Cultura. (2012). La UNESCOy "Toda persona tiene derecho a la educación". París: UNESCO. Recuperado de http://unesdoc.unesco.org/ images/0021/002127/212715s.pdf

Ors, C. (2010). La crisis del humanismo y el futuro de la filosofía. Revista Internacional de Filosofía, Suplemento 3, 125-133. ISSN: 1130-0507.

Ramírez, J. (2015). Orientación vocacional ocupacional: un análisis desde la teoría humanista existencial y la formación a nivel superior. Veritatem, 1(1), 167-188. ISSN 2215-4574.

Ramírez, J. (2013). Humanización del aprendizaje en la era de la información: una arista andragógica. Revista Actualidades Investigativas en Educación, 13(3), 1-18. https://doi.org/10.15517/aie.v13i3.12029

Ramírez, J. (2016). Repercusiones del consumismo en el proyecto de vida: un análisis desde la educación ciudadana. Revista Electrónica Educare, 20(2), 1-20. http://dx.doi.org/10.15359/ree.20-2.2

REEVO: Red de Educación Alternativa. (2012). La educación prohibida. [Documental]. Recuperado de https://www.youtube.com/watch?v=-1Y9OqSJKCc

Rodríguez, L. (2004). La causalidad. Recuperado de https://dialnet.unirioja.es/descarga/articulo/4051811. pdf

Sánchez, E. (2015). Los deberes humanos, según Saramago. Recuperado de https://lamenteesmaravillosa. com/los-deberes-humanos-segun-saramago/ 
Sant'Ana, A. (2014). Los deberes de las personas y la realización de los derechos fundamentales. Estudios Constitucionales, 12(2), 13-28. ISSN: 0718-0195.

Segura, M. \& Martínez, R. (2014). Proyecto: Apoyo a la gestión pedagógica a centros educativos de calidad con orientación inclusiva. Conexiones, 6(3), 15-23. ISSN: 1659-4487.

Sotillo, J. (2015). Desarrollo y derechos humanos: la implementación del derecho al desarrollo en el marco de la cooperación internacional y el enfoque basado en Derechos Humanos. e-dhc, (5), 12-28. Recuperado de https://www.uv.es/edhc/edhc005_sotillo.pdf

Soto, R. (2003). La inclusión educativa: una tarea que le compete a toda una sociedad. Revista Electrónica Actualidades Investigativas en Educación, 3(1), 1-17. E-ISSN: 1409-4703.

Zorrilla, M. (2002). ¿Qué relación tiene el maestro con la calidad y la equidad en educación? Conferencia dictada en el marco del Panel Calidad y Equidad en Educación en la Escuela Normal Rural "Raúl I. Burgos". Guerrero, México. 